\title{
Faktor-Faktor Yang Berhubungan Dengan Pemberian Imunisasi Dasar Pada Balita di Desa Purwajaya Kecamatan Karangampel Kabupaten Indramayu Tahun 2019
}

\author{
Factors That Influence Maternal Compliance In Providing Basic Immunization To Children \\ Under Five In Purwajaya Village Krangkeng Sub-District Indramayu District in 2019
}

\section{Nur Laeli Syukuriyah $^{1}$, Riyanto Martomijoyo ${ }^{2}$, Ade Rahmawati $^{3}$}

\author{
Program Studi Kesehatan Masyarakat Universitas Wiralodra ${ }^{1,2,3}$ \\ e-mail: nurlaelisyukuriyah5687@gmail.com, ${ }^{1}$ riyanto.martomijoyo@gmail.com, ${ }^{2}$ aderahma5286@gmail.com ${ }^{3}$
}

\begin{abstract}
Abstrak
Imunisasi merupakan upaya pencegahan penyakit, Cakupan imunisasi di Jawa Barat tahun 2017 sebesar 99,2\%, sedangkan data cakupan imunsasi Dinas Kesehatan Indramayu (71,4\%), di Puskesmas Kedungwungu 31,6\% dan di Desa Purwajaya 28,3\%. Penelitian ini berujuan untuk mengetahui faktor-faktor yang mempengaruhi kepatuhan ibu dalam pemberian imunisasi dasar pada balita di Desa Purwajaya Kecamatan Krangkeng tahun 2019. Desain penelitian ini adalah cross sectional yang dilaksanakan di Desa Purwajaya. Sampel penelitian 78 responden diambil secara accidental sampling. Pengumpulan data dilakukan dengan wawancara dan observasi. Analisis data secara univariat dan bivariat. Hasil analisis univariat diperoleh $55,1 \%$ imunisasi tidak lengkap, berpendidikan rendah $69,2 \%$, berpengetahuan kurang $23,1 \%$, keluarga yang tidak mendukung 53,8\%, Hasil analisis bivariat diperoleh pvalue pendidikan $(0,704)$ tidak memiliki hubungan yang signifikan, pengetahuan $(0,000)$ dan dukungan keluarga $(0,000)$, memiliki hubungan yang signifikan dengan pemberian imunisasi dasar pada balita. Pengetahuan dan dukungan keluarga merupakan faktor yang mempengaruhi kelangkapan pemberian imunisasi dasar pada bayi, oleh karena itu diisarankan kepada petugas kesehatan agar meningkatkan promosi kesehatan terutama tentang imunisasi.
\end{abstract}

Kata kunci: Pendidikan, Pengetahuan, Dukungan Keluarga

\section{Abstract}

Immunization is an effort to prevent disease, immunization coverage in West Java in 2017 was 99,24\%, while data on immunization coverage of the Indramayu Health Office(71,4\%), at the Kedungwungu Health Center $31,6 \%$ and in Purwajaya Village $28,3 \%$. This study aims to determine the factors that influence maternal compliance in providing basic immunization in infants at Purwajaya village, Krangkeng subdistrict, Indramayu distrct in 2019. Th design of this study was cross sectional which was carried out in Purwajaya village. Research sample 78 respondents were choosen by accidental sampling. Data collection is done by interview and observation Univariate and bivariate data analysis. Univariate analysis results obtained $55,1 \%$ incomplete immunization, low educated $69,2 \%$, knowledgeable $23,1 \%$, families that dont support 53,8\%, bivariate analysis results obtained education p-value $(0,704)$ has no significant relationship, knowledge $(0,000)$ and family support $(0,000)$, has a significant relationship with basic immunization in infant. Family knowledge and support are factors that influence the completeness of basic immunization in infants, therefore it is recommended to health workers to increase helath promotion especially about immunization.

Keywords: education, knowledge, family support.

\section{Pendahuluan}

Indonesia sehat merupakan visi pembangunan nasional yang ingin dicapai melalui pembangunan kesehatan dengan tujuan meningkatkan kualitas sumber daya manusia yang dilakukan secara berkelanjutan, dimana penduduknya hidup dalam lingkungan dan perilaku sehat, mampu memperoleh pelayanan kesehatan yang bermutu secara adil dan merata, serta memiliki derajat kesehatan yang setinggi-tingginya. ${ }^{1}$

Upaya untuk mencapai tujuan tersebut, berbagai program dengan berbasis Primary Health Care (PHC) telah dilaksanakan untuk 
meningkatkan derajat kesehatan. Beberapa indikator yang digunakan World Health Organization (WHO) untuk mengukur tingkat keberhasilan program-program tersebut, antara lain Angka Kematian Bayi (AKB), Angka Kematian Balita (AKABA) dan Angka Kematian Ibu (AKI) dan angka harapan hidup (life expectancy). Salah satu indikator Mellenium Development Goals (MDGs) adalah mengurangi kematian anak dibawah lima tahun (balita). ${ }^{2}$

Setiap tahun lebih dari 1,4 juta anak didunia meninggal karena berbagai penyakit yang sesungguhnya dapat dicegah dengan imunisasi. Beberapa penyakit yang dapat dicegah dengan imunisasi (PD3I) adalah difteri, tetanus, hepatitis $\mathrm{B}$, radang selaput otak, radang paru-paru dan polio. ${ }^{2}$

Menurut Depkes RI tanpa imunisasi, kira-kira 3 dari 100 kelahiran anak akan meninggal karena penyakit campak. 2 dari 100 kelahiran anak akan meninggal karena batuk rejan. 1 dari 100 anak akan meninggal karena penyakit tetanus. Setiap 200.000 anak, 1 akan menderita penyakit polio. Belum lagi akibat terjadi penularan akibat dari penyakit tersebut. Imunisasi berasal dari kata imun, kebal atau resisten. Jadi imunisasi adalah suatu tindakan untuk memberikan kekebalan dengan cara memasukkan antigen ke dalam tubuh manusia. $^{1}$

Pencapaian Universal Child Immunization (UCI) ialah tercapainya imunisasi dasar secara lengkap pada bayi (0-11 bulan). Desa UCI merupakan gambaran Desa atau kelurahan dengan $\geq 80 \%$ jumlah bayi yang ada di desa tersebut mendapatkan imunisasi dasar lengkap dalam waktu satu tahun. Menurut Dinas Kesehatan Provinsi Jawa Barat, Indramayu masih termasuk dalam 10
Kabupaten di Jawa Barat yang memiliki cakupan imunisasi yang rendah. Data tentang cakupan imunisasi dasar tahun 2014 hanya sebesar $85,5 \%$ desa/kelurahan, lebih tinggi dibandingkan tahun 2015 sebesar 80,2\%. Angka tersebut juga masih dibawah target tahun 2016 ang hanya memperoleh 75,0\% dan standar pelayanan minimal yang menetapkan target $100 \%$ desa/kelurahan. Berdasarkan data Kementrian Kesehatan, cakupan Universal Child Immunization (UCI) tahun 2014 adalah $75,3 \%$, pada tahun 2015 turun menjadi $74,1 \%$, untuk tahun $2016 \quad 30,9 \%$ bayi tidak terimunisasi lengkap. ${ }^{3}$

Berdasarkan Profil Keluarga Indonesia Tahun 2017 Di Jawa Barat cakupan imunisasi dasar lengkap pada bayi mencapai 99,2\% (863.931), yaitu BCG mencapai 89,2 \% (780,165), HB 7 hari mencapai 89,0 \% (778,401), DPT-HB-HIB (1) mencapai 89,0 \% (778,401), DPT-HB-HIB (2) mencapai 86,5\% (753,604) , DPT-HB-HIB (3) mencapai 86,5 $\%(753,604)$ dan untuk campak mencapai 98,0 $\%(153,483)^{3}$.

Data cakupan imunisasi lengkap Dinas Kesehatan Kabupaten Indramayu tahun 2018 tercatat bahwa jumlah cakupan imunisasi lengkap sebanyak 27.262 bayi $(71,4 \%)$ dari 38.182 bayi tersebar dalam 31 Kecamatan. Kecamatan dengan cakupan imunisasi lengkap terendah yaitu Kecamatan Sindang sebesar 42,4\%, Kecamatan Sukra 46,5\%, Kecamatan Pasekan 46,9\% dilanjut Kecamatan Haurgelis 48,9\% dan Kecamatan Krangkeng 52,0\%. Sedangkan untuk Puskesmas dengan cakupan imunisasi terendah yaitu Puskesmas Sukra 40,9\%, Kedungwungu 31,6\% dan Sindang $26,2 \%{ }^{4}$

Di Kecamatan Krangkeng terdapat dua Puskesmas dengan perbedaan cakupan 
imunisasi dasar yaitu Puskesmas Krangkeng sebanyak $68,4 \%$ dan Puskesmas Kedungwungu $\quad 31,6 \%$. Puskesmas Kedungwungu merupakan puskesmas terendah ke 2 se Kabupaten Indramayu. Berdasarkan dari laporan imunisasi Puskesmas Kedungwungu tahun 2018 tercatat sebanyak 923 bayi, 342 bayi telah mendapatkan imunisasi lengkap yang terbagi atas 5 desa, Desa Dukuh Jati 50 bayi (28,3\%), Desa Tegal Mulya 72 bayi (41,8\%), Kedungwungu 74 bayi (43,0\%), kemudian Desa Kapringan 112 bayi $(39,4 \%)$ dan yang terendah Desa Purwajaya terimunisasi 34 bayi $(28,3 \%){ }^{5}$

Menurut Ranuh, salah satu faktor yang perlu diperhatikan dalam imunisasi adalah kepatuhan jadwal imunisasi. Apabila ibu tidak patuh dalam mengimunisasi bayinya maka akan berpengaruh terhadap kekebalan dan kerentanan bayi terhadap suatu penyakit. Sehingga bayi harus mendapatkan imunisasi tepat waktu agar terlindung dari berbagai penyakit berbahaya. $^{6}$

Terkait dengan pemberian imunisasi, penting untuk mengetahui faktor-faktor apa saja yang mempengaruhi kepatuhan ibu dalam Pemberian Imunisasi Dasar pada Balita. Menurut teori perubahan perilaku Health Belief Model ada 3 kategori utama dalam pelayanan kesehatan yaitu persepsi individu, faktor-faktor modifikasi yang terdiri dari usia, jenis kelamin, pendidikan, etnis, kepribadian, sosial ekonomi, dukungan keluarga, pengetahuan serta kemungkinan tindakan.

Berdasarkan latar belakang tersebut peneliti perlu melakukan penelitian yang berjudul Faktor-Faktor Yang Mempengaruhi Kepatuhan Ibu Dalam Pemberian Imunisasi Dasar Pada Balita Di Desa Purwajaya
Kecamatan Krangkeng Kabupaten Indramayu Tahun 2019.

\section{Metode Penelitian}

Jenis penelitian yang digunakan dalam penelitian ini adalah kuantitatif yang menekankan pada penelitian numerik atas fenomena yang dipelajari. Metode penelitian yang digunakan adalah analitik dengan desain penelitian cross sectional yaitu penelitian untuk mempelajari dinamika kolerasi antara faktor-faktor risiko dengan efek, dengan cara pendekatan, observasi, atau pengumpulan data sekaligus pada suatu saat, artinya setiap subjek penelitian hanya di observasi sekali saja dan pengukuran dilakukan terhadap status karakter atau variabel subjek penelitian diamati pada waktu yang sama.

\section{Hasil \\ Deskripsi Lokasi Penelitian}

Desa Purwajaya sendiri adalah bagian dari wilayah administrasi Kecamatan Krangkeng Kabupaten Indramayu yang terdiri atas 4 Dusun/4 RW dan 17 RT. Jumlah penduduk 1.108 orang. Batas wilayah administrasi sebelah barat Desa Kapringan, sebelah Utara Desa Kapringan, sebelah Selatan Desa Sibubut dan sebelah Timur Desa Singakerta. Sedangkan jarak dari desa ke Ibu Kota Kecamatan kurang lebih 40 km, dan ke Ibu Kota Provinsi kurang lebih 250 km. ${ }^{8}$

Sarana dan prasarana Desa Purwajaya terdiri dari 3 buah Sekolah Dasar, 1 Pustu/Poskesdes, 4 Posyandu, 7 kilometer jalanan rusak dan 5 kilometer jalanan pesawahan, aparatur Desa Purwajaya terdiri dari Kepala Desa, Sekretaris Desa, Kaur Pemerintahan, Kaur Ekonomi Pembangunan, Kaur Kesra, dan Kaur Umum ${ }^{8}$. 


\section{Analisis Univariat}

Tabel 1 Distribusi Frekuensi Responden berdasarkan Kepatuhan Ibu dalam Pemberian Imunisasi Dasar pada Balita di Desa Purwajaya Kecamatan Krangkeng Kabupaten Indramayu Tahun 2019

\begin{tabular}{llcc}
\hline No & Kepatuhan & Jumlah & $\begin{array}{c}\text { Persentase } \\
\mathbf{( \% )}\end{array}$ \\
\hline $\mathbf{1}$ & Tidak Patuh & 43 & 55,1 \\
\hline $\mathbf{2}$ & Patuh & 35 & 44,9 \\
\hline & Total & 78 & 100,0 \\
\hline & Dari hasil analisis & univariat & diketahui
\end{tabular}

bahwa pada kategori kepatuhan, responden $55,1 \%$ tidak patuh.

Tabel 2 Distribusi Frekuensi Responden berdasarkan Pendidikan Ibu dalam Pemberian Imunisasi Dasar pada Balita di Desa Purwajaya Kecamatan Krangkeng Kabupaten Indramayu Tahun 2019

\begin{tabular}{llcc}
\hline No & $\begin{array}{l}\text { Pendidikan } \\
\text { Ibu }\end{array}$ & Jumlah & $\begin{array}{c}\text { Presentase } \\
(\%)\end{array}$ \\
\hline $\mathbf{1}$ & Rendah & 54 & 69,2 \\
\hline $\mathbf{2}$ & Tinggi & 24 & 30,8 \\
\hline & Total & 78 & 100,0 \\
\hline
\end{tabular}

Ibu yang berlatar belakang pendidikan tinggi lebih sedikit dibandingkan dengan ibu yang berlatar belakang pendidikan rendah sebanyak $69,2 \%$.

Tabel 3 Distribusi Frekuensi Responden berdasarkan Pengetahuan Ibu dalam Pemberian Imunisasi Dasar pada Balita di Desa Purwajaya Kecamatan Krangkeng Kabupaten Indramayu Tahun 2019

\begin{tabular}{llrc}
\hline No & $\begin{array}{c}\text { Pengetahuan } \\
\text { Ibu }\end{array}$ & Jumlah & $\begin{array}{c}\text { Presentase } \\
(\mathbf{\%})\end{array}$ \\
\hline $\mathbf{1}$ & Kurang Baik & 18 & 23,1 \\
\hline $\mathbf{2}$ & Baik & 60 & 76,9 \\
\hline & Total & 78 & 100,0 \\
\hline & Analisis $\quad$ unvariat & pada & variabel
\end{tabular}

pengetahuan menunjukkan bahwa ibu yang memiliki pengetahuan baik lebih banyak
$(76,9 \%)$ dibandingkan dengan ibu yang berpengetahuan kurang baik $(23,1 \%)$.

Tabel 4 Distribusi Frekuensi Responden berdasarkan Pengetahuan Ibu dalam Pemberian Imunisasi Dasar pada Balita di Desa Purwajaya Kecamatan Krangkeng Kabupaten Indramayu Tahun 2019

\begin{tabular}{llcc}
\hline No & $\begin{array}{l}\text { Dukungan } \\
\text { Keluarga }\end{array}$ & Jumlah & $\begin{array}{c}\text { Presentase } \\
(\%)\end{array}$ \\
\hline $\mathbf{1}$ & $\begin{array}{l}\text { Tidak } \\
\text { Mendukung }\end{array}$ & 42 & 53,8 \\
\hline $\mathbf{2}$ & Mendukung & 36 & 46,2 \\
\hline & Total & 78 & 100,0 \\
\hline & Analisis univariat dukungan & keluarga
\end{tabular}
dengan keluarga yang tidak mendukung lebih tinggi $(53,8 \%)$ dibandingkan dengan keluarga yang mendukung pemberian imunisasi dasar $(46,2 \%)$.

\section{Analisis Bivariat}

Analisis bivariat dilakukan untuk mengetahui variabel independen (pendidikan, pengetahuan dan dukungan keluarga) dengan variabel dependen (Kepatuhan Ibu dalam pemberian imunisasi dasar pada balita).

Tabel 5 Hubungan Pendidikan Ibu dengan Pemberian Imunisasi Dasar pada Balita di Desa Purwajaya Kecamatan Krangkeng Kabupaten Indramayu Tahun 2019.

\begin{tabular}{|c|c|c|c|c|c|}
\hline \multirow{3}{*}{$\underset{n}{\text { Kepatuha }}$} & \multicolumn{3}{|c|}{ Pendidikan Ibu } & \multirow{2}{*}{\multicolumn{2}{|c|}{ Total }} \\
\hline & $\begin{array}{c}\text { Rendah } \leq \\
\text { SMP }\end{array}$ & & $\begin{array}{l}\text { gi > } \\
\text { IP }\end{array}$ & & \\
\hline & $\%$ & $\mathbf{N}$ & $\%$ & $1 v$ & $\%$ \\
\hline
\end{tabular}

$\begin{array}{lllllll}\text { Tidak } & 29 & 53,7 & 14 & 58,3 & 43 & 55,1\end{array}$

$\begin{array}{llllll}\text { Lengkap } & 0,704\end{array}$

\begin{tabular}{lllllll}
\hline Lengkap & 25 & 46,3 & 10 & 41,7 & 35 & 44,9
\end{tabular}

$\begin{array}{lllllll}\text { Total } & 54 & 100 & 24 & 100 & 78 & 100\end{array}$

Analisis statistik variabel tingkat pendidikan responden memperoleh nilai $\mathrm{p}$ value sebesar $0,704(\mathrm{p}>0,05)$, artinya tidak terdapat hubungan yang bermakna antara pendidikan ibu dengan pemberian imunisasi dasar pada balita di Desa Purwajaya. 
Tabel 6 Hubungan Pengetahuan Ibu dengan Pemberian Imunisasi Dasar pada Balita di Desa Purwajaya Kecamatan Krangkeng Kabupaten Indramayu Tahun 2019

\begin{tabular}{|c|c|c|c|c|}
\hline \multirow{3}{*}{ Kepatuhan } & \multicolumn{2}{|c|}{ Pengetahuan Ibu } & \multirow[b]{2}{*}{ Total } & \\
\hline & $\begin{array}{c}\text { Kurang } \\
\text { Baik }\end{array}$ & Baik & & $\begin{array}{c}P- \\
\text { Value }\end{array}$ \\
\hline & $\%$ & $\%$ & $\mathbf{N}$ & \\
\hline
\end{tabular}

\begin{tabular}{lccccccc}
\hline $\begin{array}{l}\text { Tidak } \\
\text { Lengkap }\end{array}$ & 18 & 100 & 25 & 41,7 & 43 & 55,1 & 0,000 \\
\cline { 1 - 6 } Lengkap & 0 & 0 & 35 & 58,3 & 35 & 44,9 \\
\hline Total & 18 & 100 & 60 & 100 & 78 & 100 & \\
\hline
\end{tabular}

Analisis statistik variabel pengetahuan responden memperoleh nilai $\mathrm{p}$-value sebesar $0,000(\mathrm{p}<0,05)$, artinya terdapat hubungan yang bermakna antara pengetahuan ibu dengan pemberian imunisasi dasar pada balita di Desa Purwajaya Kecamatan Krangkeng Kabupaten Indramayu Tahun 2019.

Tabel 7 Hubungan Dukungan Keluarga dengan Pemberian Imunisasi Dasar pada Balita di Desa Purwajaya Kecamatan Krangkeng Kabupaten Indramayu Tahun 2019

\begin{tabular}{|c|c|c|c|c|c|c|c|}
\hline \multirow{3}{*}{$\begin{array}{l}\text { Kepa } \\
\text { tuhan }\end{array}$} & \multicolumn{4}{|c|}{ Dukungan Keluarga } & \multirow{2}{*}{\multicolumn{2}{|c|}{ Total }} & \\
\hline & \multicolumn{2}{|c|}{$\begin{array}{c}\text { Tidak } \\
\text { Mendu } \\
\text { kung }\end{array}$} & \multicolumn{2}{|c|}{$\begin{array}{l}\text { Mendu } \\
\text { kung }\end{array}$} & & & $\begin{array}{c}P \text { - } \\
\text { Value }\end{array}$ \\
\hline & $\mathbf{N}$ & $\%$ & $\mathbf{N}$ & $\%$ & $\mathbf{N}$ & $\%$ & \\
\hline $\begin{array}{l}\text { Tidak } \\
\text { Lengkap }\end{array}$ & 33 & 78,6 & 10 & 27,8 & 43 & $\begin{array}{c}55 \\
1\end{array}$ & 0,00 \\
\hline Lengkap & 9 & 21,4 & 26 & 72,2 & 35 & $\begin{array}{c}44 \\
9\end{array}$ & 0 \\
\hline Total & 42 & 100 & 36 & 100 & 78 & 100 & \\
\hline
\end{tabular}

keluarga responden memperoleh nilai $\mathrm{p}$-value sebesar 0,000 ( $\mathrm{p}<0,05)$, artinya terdapat hubungan yang bermakna antara dukungan keluarga dengan pemberian imunisasi dasar pada balita di Desa Purwajaya Kecamatan Krangkeng Kabupaten Indramayu Tahun 2019.

\section{Pembahasan}

Responden yang berpendidikan rendah lebih tinggi dibandingkan responden yang berpendidikan tinggi. Hasil analisis statistik variabel tingkat pendidikan responden pada tabel 5 memperoleh nilai p-value 0,704 $(\mathrm{p}>0,05)$ artinya tidak terdapat hubungan antara pendidikan ibu dengan pemberian imunisasi dasar pada balita di Desa Purwajaya Kecamatan Krangkeng Kabupaten Indramayu Tahun 2019. Dari hasil penelitian yang dilakukan diketahui bahwa responden yang memiliki pendidikan tinggi lebih banyak tidak memberikan imunisasi secara lengkap terhadap balitanya, begitupun untuk ibu yang berlatarbelakang pendidikan rendah sehingga pendidikan stidak menjadi alasan rendahnya cakupan imunisasi dasar lengkap pada balita di Desa Purwajaya Kecamatan Krangkeng Kabupaten Indramayu Tahun 2019.

Tingkat pendidikan ibu merupakan faktor penting yang mengatur persepsi orang tua tentang imunisasi. Pengaruh tingkat pendidikan terhadap penggunaan fasilitas pelayanan kesehatan, bahwa penggunaan posyandu dipengaruhi oleh tingkat pendidikan dapat membuat orang menjadi berpandangan lebih luas berfikir dan bertindak secara rasional sehingga latar belakang pendidikan seseorang dapat mempengaruhi penggunaan pelayanan kesehatan. ${ }^{9}$

Pengetahuan adalah hasil pengindraan manusia atau hasil tahu seseorang terhadap objek melalui indra yang dimilikinya (mata, hidung, telinga dan sebagainya) dengan sendirinya pada waktu pengindraan. Sehingga menghasilkan pengetahuan tersebut sangat dipengaruhi oleh intensitas perhatian dan persepsi terhadp objek. Sebagian besar pengetahuan seseorang diperoleh melalui indra pendengaran (telinga), indra penglihatan (mata). ${ }^{3}$

Orang yang memiliki pengetahuan tentang sesuatu hal maka orang tersebut akan mengaplikasikan pengetahuannya tersebut dalam kehidupan sehari-hari, begitu juga dengan masalah imunisasi, ibu yang memiliki pengetahun tinggi tentang imunisasi maka dia akan melakukan imunisasi dan tahu kapan waktu yang tepat pemberian imunisasi, 
begitupun sebaliknya. Oleh karena itu tindakan yang tepat untuk menigkatkan pengetahuan responden adalah mengupayakan agar terlaksananya penyuluhan rutin kepada masyarakat terutama ibu yang memiliki bayi, penyuluhan ini dapat dilaksanakan di puskesmas, pustu ataupun posyandu baik secara individu maupun kelompok, penyuluhan juga dapat dilakukan dengan penyebaran leaflet/poster/media sosial. ${ }^{10}$

Pengetahuan tentang imunisasi mencakup tahu akan pengertian imunisasi, jenis imunisasi dan jumlah pemberian imunisasi. Melalui pengetahuan yang cukup diharapkan dapat mempengaruhi tindakan seorang ibu dalam memberikan imunisasi secara lengkap kepada anaknya sesuai dengan hasil Chi Square diperoleh nilai p-value 0,000 $(\mathrm{p}<0,05)$ dengan demikian dapat disimpulkan bahwa ada hubungan antara pengetahuan ibu dengan pemberian imunisasi dasar pada balita.

Kehidupan dalam suatu lingkungan mutlak adanya interaksi sosial hubungan antara dua atau lebih individu yang saling mempengaruhi lingkungan rumah dan masyarakat dimana individu melakukan interaksi sosial merupakan faktor yang dapat mempengaruhi kelengkapan imunisasi dasar terutama lingkup terkecil yaitu keluarga. ${ }^{11}$

Orang yang mendapatkan dukungan dari keluarga tentang sesuatu hal maka orang tersebut akan berpotensi untuk melakukan tindakan tersebut dalam kehidupan sehari-hari, begitu juga dengan masalah imunisasi, individu yang memperoleh dukungan keluarga yang tinggi akan menjadi individu yang lebih optimis dalam menghadapi masalah kesehatan dan kehidupan dan lebih terampil dalam memenuhi kebutuhan psikologi. ${ }^{12}$

Melalui dukungan keluarga diharapkan dapat mempengaruhi tindakan seorang ibu dalam memberikan imunisasi dasar kepada anaknya sesuai dengan hasil analisis dengan uji Chi Square penelitian ini yang menghasilkan $p$-value $0,000(\mathrm{p}<0,05)$ sehingga dapat disimpulkan bahwa adanya hubungan antara dukungan keluarga dengan pemberian imunisasi dasar pada balita.

\section{Kesimpulan}

Hampir separuh responden yang tidak mendapatkan imunisasi dasar, berpengetahuan rendah, tidak mendapat dukungan dari keluarga dengan latar belakang pendidikan yang rendah. Variabel yang tidak berhubungan dalam penelitian ini adalah faktor pendidikan ibu dengan kelengkapan pemberian imunisasi dasar pada balita di Desa Purwajaya Kecamatan Krangkeng Kabupaten Indramayu Tahun 2019.

Peneliti menyarankan kepada aparatur desa agar memberikan penyuluhan tentang pentingnya berpendidikan tinggi, tujuan pendidikan salah satunya adalah untuk mencerdaskan sehingga keluarga yang cerdas akan menghasilkan anak yang cerdas pula, sedangkan variabel yang berhubungan dalam penelitian ini adalah pengetahuan ibu dan dukungan keluarga dengan kelengkapan pemberian imunisasi dasar pada balita, disinipun peneliti menyarankan kepada tenaga kesehatan agar dapat membangun pengetahuan responden dalam bidang kesehatan terutama imunisasi dengan cara penyuluhan, pembagian leaflet ataupun media sosial, bentuk penyuluhan dapat secara perorangan maupun kelompok dengan jadwal yang telah ditentukan dan kontiniu sehingga semakin tumbuh kesadaran responden tentang pentingnya kesehatan terutama berkaitan dengan imunisasi dasar.

\section{Daftar Pustaka}

1. Kemenkes Republik Indonesia, 2014, Data dan Informasi Profil Kesehatan Indonesia 2013, Kementerian Kesehatan RI.

2. Triana, Vivi., 2016, Faktor yang Berhubungan dengan Pemberian Imunisasi Dasar lengkap pada bayi Tahun 2015, Universitas Andalas, 
Padang, Sumatra Barat

3. Kemenkes Republik Indonesia, 2017, Data dan Informasi Profil Kesehatan Indonesia 2016, Kementrian Kesehatan RI.

4. Dinas Kesehatan Kabupaten Indramayu, 2019, Laporan Tahunan Cakupan Imunisasi Tahun 2018, DINKES Kabupaten Indramayu.

5. Profil Kesehatan Provinsi Jawa Barat, 2012, Profil Kesehatan Provinsi Jawa Barat.

6. I.G.N Gde Ranuh, Dkk, 2011, Pedoman Imunisasi di Indonesia, Badan Penerbit Ikatan Dokter Indonesia.

7. Kemenkes Republik Indonesia, 2018, Data dan Informasi Profil Kesehatan Indonesia 2017, Jakarta.

8. Desa Purwajaya, 2018, Profil Desa Purwajaya, Indramayu

9. Direktorat Jenderal PP\&PL Departemen Kesehatan R.I, 2015, Pedoman Teknis Imunisasi Tingkat Puskesmas, Jakarta, Bakti Husada, UNICEF.

10. Nurul Huda, 2009, Gambaran Pengetahuan, Sikap dan Perilaku Ibu tentang Imunisasi Dasar Lengkap di Puskesmas Ciputat Tahun 2009, UIN Syarif Hidayatulloh, Jakarta.

11. Pipit Astini, 2014, Faktor-faktor yang Mempengaruhi Status Kelengkapan Imunisasi di Desa Karang Bawang Kecamatan Rembang Tahun 2014, Universitas Muhammadiyah Purwokerto.

12. Setiadi, 2008, Konsep dan Proses Keperawatan Keluarga, Surabaya: Graha Ilmu. 